Article

\title{
Barrier Analysis for the Deployment of Renewable-Based Mini-Grids in Myanmar Using the Analytic Hierarchy Process (AHP)
}

\author{
Masako Numata ${ }^{1, *(1)}$, Masahiro Sugiyama ${ }^{1}$ and Gento Mogi ${ }^{2}$ \\ 1 Institute for Future Initiatives, The University of Tokyo, Tokyo 113-0033, Japan; masahiro@ifi.u-tokyo.ac.jp \\ 2 Department of Technology Management for Innovation (TMI), School of Engineering, The University of \\ Tokyo, Tokyo 113-0033, Japan; mogi@tmi.t.u-tokyo.ac.jp \\ * Correspondence: m.matsuo-numata@05.alumni.u-tokyo.ac.jp
}

Received: 31 January 2020; Accepted: 8 March 2020; Published: 17 March 2020

check for updates

\begin{abstract}
Energy access remains a challenge for many countries, as recognized by sustainable development goal 7 of the United Nations Development Programme. Although the Myanmar government has set a target of $100 \%$ electrification by 2030, less than half of the households are currently connected to the national grid. To expedite electrification, decentralized approaches should be considered. Mini-grids are an effective alternative that can fill the gap between a solar home system and the national grid; however, many of the existing mini-grids in Myanmar are powered by diesel generators. Diesel fuel is significantly more expensive in rural areas than in urban areas due to high transportation costs. Although mini-grids powered by solar photovoltaics and batteries are cost-competitive with diesel generators, the deployment of renewable energy-based mini-grids is slow. In this study, we analyzed the barriers to mini-grid deployment and prioritized the barriers. We conducted a questionnaire survey with stakeholders using the analytic hierarchy process to identify the prioritization of each barrier factor. The K-means clustering method was used to determine tendencies and showed that there was no single, dominant solution. Our results confirm the difficulty of mini-grid deployment and suggest multi-pronged approaches that go beyond economic considerations.
\end{abstract}

Keywords: AHP; barrier; energy access; rural electrification; Myanmar; mini-grid; micro-grid; renewable energy

\section{Introduction}

Sustainable development goal 7 of the United Nations Development Programme ("Affordable and clean energy") recognizes that access to electricity remains a global issue. The global population without access to electricity decreased to 840 million in 2017 [1]. Considering the present environmental crisis, electricity should be provided through the expansion of renewable energy technologies instead of fossil-fuel-based systems. Sub-Saharan Africa has attracted much attention because a large part of its population does not have access to electricity. In Asia, however, Myanmar has nearly the same electrification rate as that of sub-Saharan Africa [2]. The number of households connected to the national grid has increased from 34\% in 2016 [3] to $42 \%$ in 2018 [4]. The Myanmar government has set a target of $100 \%$ electrification by 2030 [5]. Although the national grid accounts for over $80 \%$ of the electrification in urban areas, it accounts for less than $13 \%$ in rural areas, which is quite low considering that 36 million people ( $70 \%$ of the population) live in rural areas in Myanmar [6]. Moreover, electrification using mini-grids is approximately 13\% [7]. It is estimated that an additional $37 \%$ and $44 \%$ of power sources need to be added to the main and mini-grids, respectively, to ensure universal 
energy access in the developing Asian countries [8]. It is also suggested that actions should not be solely focused on the extension of the national grids.

Mini-grids have recently attracted considerable attention for being the bridge between household electrification methods, such as solar lanterns and solar home systems (SHSs), and large-scale national grids $[9,10]$. Myanmar has abundant renewable energy resources. The potential capacities of solar power are estimated to be $27,0.23$, and $100 \mathrm{GW}$ for small-scale, medium-scale, and large-scale hydropower systems, respectively [11,12]. However, renewable energy resources have not been given due consideration in the planning of electricity generation [13]. In the Power Resource Balance Scenario of the National Electricity Master Plan, which has been developed with the support of the Japan International Cooperation Agency and chosen as the scenario for universal access in 2019 [14], the renewable energy share has been set as only 9\% of the installed capacity in 2030 [15]. Myanmar's Nationally Determined Contributions to the Paris Agreement claims that the country will "implement mitigation actions in line with sustainable development needs" [16]. Therefore, the country should use its abundant resources not only for large-scale power generation, but also as a power source for mini-grids [17].

In Myanmar, diesel is the dominant mini-grid power source in terms of the number of villages powered. In 2016, diesel generators powered 13,000 villages through mini-grids, whereas hydropower, biomass, and solar energies were used by 2400,1200 , and 150 villages, respectively [18]. Although various international aid agencies promote the introduction of mini-grids combining solar power and storage batteries [19-21], the use of mini-grids is not expanding rapidly. Solar and battery-based mini-grids were found to be cost-competitive in terms of the levelized cost of electricity in rural areas, where diesel fuel is significantly more expensive than in urban areas [22].

Therefore, it is crucial to determine the different barriers (techno-economic and other barriers) that hamper the deployment of renewable-energy-based mini-grids. In this study, we constructed a barrier typology based on discussions with stakeholders (international organizations, private companies, non-governmental organizations, and field researchers) through a bibliographic survey and analyzed the priority of each barrier through a questionnaire survey of stakeholders using an analytic hierarchy process (AHP).

The AHP has been applied to energy-related topics, for example, the prioritization of decentralized power in Iran [23] and Jordan [24], development of energy in rural China [25], selection of suitable locations for wind power generation [26], and researching long-term energy resource and development planning in Korea [27]. Several studies have applied the AHP for barrier analysis, for example, small-scale power sources in Sri Lanka [28], the adaptation of renewable energy in India [29] and Nepal [30], cooking stoves and biogas fermenters in rural Thailand [31], energy efficiency in small-scale industries in India [32], and cleaner production by small and medium-sized enterprises in China [33]. Although the consensus indicator of the AHP is a relatively new concept $[34,35]$, it has been applied to discussing the determinant of foreign direct investment for the development of solar and wind energies in developing countries [36]. We performed an in-depth analysis of the results using the consensus indicator.

\section{Methodology}

\subsection{Framework for Barriers}

To analyze the barriers to the deployment of renewable-energy-based mini-grids in Myanmar, we applied the following approach for barrier identification: (1) literature review, (2) site visits, and (3) interaction with stakeholders [37]. This barrier typology has been applied widely in the energy sector [38-42].

First, we conducted a broad literature review regarding the barriers to the use of renewable energies and mini-grids in developing countries, including a typology [39]. Second, we rebuilt the barrier typology in the context of Myanmar through discussions with the stakeholders. Observations 
were included from the site visits to solar mini-grids and diesel-powered mini-grids in Mandalay Region in 2017 and Magway Region in 2018. The prioritized barrier factors listed herein were discussed.

\subsection{Analytic Hierarchy Process (AHP)}

Various multi-criteria decision-making methods can be applied to energy fields [43]; however, we chose the AHP because it is widely used and easy to understand. The AHP is a decision-making method developed by Saaty in the 1970s, which subsequently became popular [44-46]. In the AHP, a problem is hierarchically structured, and a paired comparison of each factor is defined to rank its importance. The procedure is as follows [47]:

1. The problem is modeled by considering the hierarchy of key factors.

2. The importance of the elements is determined by comparing the pairs based on knowledge and emotion, where they are scored using the importance scale shown in Table 1.

3. Each factor is prioritized by calculating the eigenvalue of the judgment matrices.

4. The consistency of the scores from the respondents is checked using the consistency ratio (C.R.).

5. The average of the consistent weights $(C . R .<0.2)$ in each category is taken.

Table 1. Fundamental scale [48].

\begin{tabular}{lc}
\hline 1 & Equal importance \\
3 & Moderate importance \\
5 & Strong importance \\
7 & Very strong importance \\
9 & Extreme importance \\
\hline
\end{tabular}

From the pair-wise comparisons made by the respondents, judgments were obtained as square matrices (we chose four factors, thus a $4 \times 4$ matrix was created) with diagonal components. The results were checked for consistency using the C.R. from the random index (R.I.) (Table 2) (0.89 for a matrix of $n=4)$ and the consistency index (C.I.) calculated from Equation (1) [48]. C.R. is calculated using Equation (2).

$$
\text { C.I. }=\frac{\lambda_{\max }-n}{n-1}
$$

Here, $\lambda_{\max }$ is the maximum eigenvalue of the judgment matrix and $n$ is the number of factors.

$$
\text { C.R. }=\frac{\text { C.I. }}{\text { R.I. }}
$$

Table 2. Random index (R.I.) [48].

\begin{tabular}{ccccccccccc}
\hline Matrix Order & $\mathbf{1}$ & $\mathbf{2}$ & $\mathbf{3}$ & $\mathbf{4}$ & $\mathbf{5}$ & $\mathbf{6}$ & $\mathbf{7}$ & $\mathbf{8}$ & $\mathbf{9}$ & $\mathbf{1 0}$ \\
\hline R.I. & 0 & 0 & 0.52 & 0.89 & 1.11 & 1.25 & 1.35 & 1.40 & 1.45 & 1.49 \\
\hline
\end{tabular}

In this study, C.R. was set as 0.2 and only the results whose C.R. was below 0.2 were used for analysis. It has been reported that the C.R. should never be more than 0.2 [49]. Some previous studies have adopted a C.R. of 0.1 [26,50]; however, in reality, it is difficult to obtain highly consistent answers, and thus, many studies have adopted a C.R. of 0.2 [36,51-53].

\section{Indicator for Consensus}

When judgments are elicited in groups, the geometric mean of the judgments is taken [49]. However, it is often difficult to achieve consensus among stakeholders. Although it has been reported that judgments can be revised [49], in reality, it is difficult to request stakeholders to revise their decision 
multiple times. The consensus indicator $\left(S^{*}\right)$ was developed to discuss the consensus level of group decisions [34] based on Shannon entropy $(H)$ [54]:

$$
S^{*}=\frac{\frac{\exp \left(H_{\alpha}\right)}{\exp \left(H_{\gamma}\right)}-\frac{\exp \left(H_{\alpha \min }^{*}\right)}{\exp \left(H_{\gamma \max }^{*}\right)}}{1-\frac{\exp \left(H_{\alpha \min }^{*}\right)}{\exp \left(H_{\gamma \text { max }}^{*}\right)}},
$$

where $H_{\alpha}$ is the average Shannon entropy of all the individuals, and $H_{\gamma}$ is the stakeholders' aggregated priorities for priorities $p_{i j}$ for each of the $n$ factors from each of the $K$ stakeholders [55]:

$$
\begin{gathered}
H_{\alpha}=-\frac{1}{K} \sum_{i=1}^{n} \sum_{j=1}^{K} p_{i j} \ln p_{i j} \\
H_{\gamma}=\sum_{i=1}^{n}\left\{-\left(\frac{1}{K} p_{i 1}+\frac{1}{K} p_{i 2}+\ldots+\frac{1}{K} p_{i K}\right) \times \ln \left(\frac{1}{K} p_{i 1}+\frac{1}{K} p_{i 2}+\ldots+\frac{1}{K} p_{i K}\right)\right\} .
\end{gathered}
$$

When the weight is equal for each stakeholder, it is $1 / K$.

The minimum $H_{\alpha}$ is expressed as follows [34,35]:

$$
\begin{aligned}
H_{\alpha \min }^{*} & =-\frac{M}{n+M-1} \ln \frac{M}{n+M-1}-\frac{n-1}{n+M-1} \ln \frac{1}{n+M-1} \\
& =-\frac{M}{n+M-1} \ln M-\ln \frac{1}{n+M-1} .
\end{aligned}
$$

In particular, maximum $H_{\gamma}$ can be simplified to [35]:

$$
H_{\gamma \max }^{*}=\ln (n) .
$$

Here $M$ is the maximum number of the fundamental scale (9) (Table 1). Equation (3) can be simplified to [35]:

$$
S^{*}=\frac{\frac{\exp \left(H_{\alpha}\right)}{\exp \left(H_{\gamma}\right)}-\frac{\exp \left(H_{\alpha \min }^{*}\right)}{n}}{1-\frac{\exp \left(H_{\alpha \min }^{*}\right)}{n}} .
$$

The consensus indicator ranges from $0 \%$, which implies no consensus among the stakeholders, to $100 \%$, which implies complete consensus.

It has been reported that the AHP can be used with a small sample if the experts on an issue are the respondents [36]. Therefore, the AHP can be applied to the present study in Myanmar where it is difficult to conduct an online survey with large samples. Furthermore, the required number of responses is still under discussion and varies for different studies, including 4 (conducted only by authors) [38], 13 [56], 19 [36], to 70 [57], and simulated variation from 19 to more than 400 according to the expected weights of the alternatives [58].

In this study, we applied the AHP to analyze the barriers to the deployment of mini-grids powered by renewable energy in Myanmar. Based on our barrier typology, we chose four factors in each barrier category, for which a pair comparison was performed. We categorized the barriers into five groups, and asked the respondents to compare 30 pairs, which involved six sets for each of the five barrier categories. The numbers of factors and categories were carefully chosen such that the respondents had little difficulty responding to the survey. The survey questionnaire was distributed between September 2018 and February 2019. The questionnaire papers or electronic files were sent to the stakeholders by email or in-person because online surveys are not yet popular in Myanmar. Table 3 presents the list of respondents. Energy-related stakeholders were selected from various occupations; approximately 50 questionnaires were sent and 42 responses were received for analysis. 
Table 3. Details of the questionnaire survey.

\begin{tabular}{ccc}
\hline No. of Respondents (Individuals) & Sent & Answered \\
\hline NGO (international + local) & 8 & 8 \\
Government & 8 & 7 \\
Private Company & 25 & 15 \\
Media & 2 & 2 \\
Academia & 6 & 6 \\
International Organization & 4 & 4 \\
Total & 53 & 42 \\
\hline
\end{tabular}

\subsection{K-Means Clustering}

From the consensus viewpoint, the clustering of results allows for an in-depth analysis [34]. Therefore, we used the K-means clustering method, which is a non-hierarchical clustering algorithm [59]. In this method, the values are partitioned to the nearest cluster, which has the nearest mean value within the cluster. The number of clusters is given, and the classification is based on the following process.

1. Each data point is allocated to a cluster at random, where the number of clusters is set.

2. The centroid (arithmetic mean) of each cluster is calculated.

3. The square of the distance (difference) between each data point and the centroid of the cluster is calculated.

4. Each data point is reassigned to the centroid cluster with the smallest distance (for which the difference square is minimum).

5. Recalculation is performed until the allocation of each data cluster does not change.

The elbow method and silhouette analysis method were used to evaluate the number of clusters. In the elbow method, the sum of the squared errors for each cluster number is calculated, and a line graph is plotted [60]. The number of clusters in the elbow-like bend is the reference that can be used to determine the lack of effect of increasing the number of clusters. This occurs when the number of clusters increases and is subdivided, but the decrease in the sum of the squared errors is insignificant. Data sets rarely have a distinct elbow-like bend.

Silhouette analysis shows the distance between each point in one cluster and the neighboring clusters in the range of -1 to 1 [61]. If the coefficient of a point is nearly 1 , then the point is far from the neighboring clusters. However, a coefficient of nearly zero indicates that the point is close to the boundary between the clusters. A negative coefficient indicates that the point may belong to the wrong cluster. When the silhouette plots with different numbers of clusters were compared, a reasonable number of clusters were found. We applied the K-means method to cluster the results when there was a poor consensus among the stakeholders.

\section{Barriers to the Deployment of Renewable-Energy-Based Mini-Grids}

\subsection{Barrier Typology}

We chose four barrier factors in each category for which a paired comparison was performed using the AHP [37]. The respondents were asked to compare 30 sets, which involved six sets of factors for each of the five barrier categories. The number of factors and categories were carefully chosen such that the respondents had little difficulty in responding to the survey. The barrier factors are explained below.

\subsubsection{Technical Barriers}

- Technology gap

Mini-grids powered by small-scale hydropower or biomass were developed spontaneously in Myanmar during the closure of the country under the military junta [62]. Devices, such as hydro 
turbines, have been developed indigenously, and although the design standards might be different from the current international standards, it should not be disallowed and its affordability should be evaluated.

- $\quad$ Operation and maintenance (O\&M) $[39,63,64]$

Off-grid villages have not been electrified; hence, electrical engineers are unavailable. Operating companies should start training workers for O\&M, which will increase local employment. Appropriate O\&M can improve durability and reliability.

- Intermittency $[29,39,65]$

The generation of renewable energy sources is more or less intermittent. For example, solar resources vary daily and seasonally, water volume for hydropower fluctuates seasonally, and the availability of biomass, such as rice husk, varies with the harvest season.

- Lack of interoperability with the national grid [39]

The regulations or codes for mini-grids are not established and are still under discussion. Mini-grids can be designed without considering the connection to the national grid. Thus, if there is an unexpected grid extension, the investment in the mini-grid is wasted.

\subsubsection{Regulatory Barriers}

- $\quad$ Lack of regulatory framework $[29,37,42,66]$

There is no regulatory framework for mini-grids yet. Although regulations have been discussed and drafted, they have not yet been published [67].

- Institutional capacity $[29,39,42,68-70]$

The administration in Myanmar appears to operate in silos, and a strong policy is required for good coordination among the ministries. The energy sector is now under the jurisdiction of the Ministry of Electricity and Energy (MOEE) after the structural changes to the ministries in 2016. However, the jurisdiction of each sub-sector is complicated. Off-grid electrification is managed by the Department of Rural Development of the Ministry of Agriculture, Livestock and Irrigation (DRD); petroleum, geothermal, and electricity are managed by the MOEE; coal is managed by the Ministry of Mineral Resource and Environmental Conservation; civilian nuclear energy is managed by the Ministry of Education (MOE); energy efficiency and conservation is managed by the Ministry of Industry; research and capacity building of renewable energy was led by the MOE, and subsequently the Ministry of Agriculture, Livestock and Irrigation, MOEE, and the Ministry of Mineral Resource and Environmental Conservation. It has been pointed out that this complicated structure should be streamlined [17].

- $\quad$ Lack of technical standards and codes $[37,39,65,71]$

Without technical standards or codes, it is difficult to maintain a certain level of quality for mini-grids. Regulations should be established for industrial waste, tar, and lead acid for the wastes of solar photovoltaic (PV) modules and lead acid batteries.

- Threat of grid extension $[39,69,72-74]$

The area of subsidized renewable mini-grids has been decided based on the national grid expansion plan; however, the change of plan has not been communicated promptly, and the national grid may arrive before it is planned. In addition, issues such as becoming a small power producer or compensation for businesses have not been finalized; therefore, mini-grid operators carry a potential risk. 


\subsubsection{Economic Barriers}

- $\quad$ Small market size $[29,37,69,75]$

Electricity generation from renewable energies, especially solar PVs and wind, is increasing rapidly worldwide, and mini-grids are becoming widespread. However, the Myanmar market has just been established and is still developing.

\section{- $\quad$ Low demand $[37,68,69,75]$}

Creating demands apart from the basic applications, such as lighting and charging mobile phones, remains a challenge for operators. There is no long-time data for electrification in off-grid villages. Electrification through the national grid led to a rapid installation of TVs, videos, refrigerators, rice cookers, and cooking stoves in villages. With the electrification of the Tindaungyi village (Tindaun Village tract, Kyaukse Township, Kyaukse District, Mandalay Region) in 1994, 18 out of 156 households installed meters, which implied that they could connect to the national grid at that time. Five households owned TVs, one owned a video player, and two owned refrigerators. The villager who owned the video player made an income by showing videos to the villagers. One villager who owned a refrigerator made ice candies and sold them to children on their way home from school. At an early stage, electrical appliances can be capital goods rather than durable consumer goods [76]. Unlike the national grid, mini-grid businesses require enough demand to pay for electricity generation within the area and the creation of demand becomes more important. Telecom towers as anchor customers are a good example; however, telecom towers are not always present near an off-grid village. Agriculture is the main industry in rural areas; therefore, agricultural machinery (e.g., power tiller, cultivating roller boat, thresher, combine harvester, and transplant) can be an important source of demand once a village is electrified [77].

\section{- $\quad$ Tariff structure $[39,65,68,69,73,74]$}

There is no one-size-fits-all tariff structure [78]. Many factors need to be considered when designing tariffs, such as for the energy $(\mathrm{kWh})$ or power $(\mathrm{kW})$ base, pre-paid or post-paid payment systems, and the number of lights or other appliances. In addition, customers are normally classified as industrial or residential, and there are payment exemptions for low-income households.

Tariff design affects the revenue collection. Pre-paid cards are the main payment system for the current Myanmar mini-grids; however, there are no regulations for mini-grid tariffs related to regulatory barriers. In the absence of a legal basis, operators are under pressure to reduce tariffs.

Because agriculture is the main industry in villages, customers' incomes could be seasonal, and there is not enough variety in their incomes to spread it through the off-season. Operators need to consider the industrial structure of villages and the residents' incomes based on seasonality.

- $\quad$ Fee collection $[69,73,79,80]$

This is related to the previous barrier of tariff structure, whereby companies need to be able to maintain their revenue collection rate. The pay-as-you-go (PAYG) technology is one of the pre-paid methods. As soon as customers pay the tariff, the operators unlock their access and the customers can use electricity. The PAYG system enables operators to reduce the cost of bill collection and prevent free riders.

\subsubsection{Social/Cultural Barriers}

- Negative side effects caused by international organizations [65]

The existing local mini-grids in Myanmar were intended for social welfare and were not profit-oriented. A stakeholder pointed out that the mini-grids in Myanmar developed independently 
from the international business environment; they were driven by the private sector and hence were not reflected in government statistics. Moreover, they were community-based and often a household in a village worked as an operator, with target returns that were very low or sometimes nearly zero. The business model of a subsidized renewable energy mini-grid, however, became popular, and the relationship between the operators' customers became aggravated. Customers heard about the profitability of the subsidized mini-grids and became skeptical about their mini-grids.

In addition, a heavy subsidy can distort the equipment market and should be designed carefully.

- Educational gap

A stakeholder raised the point that the educational gap makes it difficult for local companies to obtain financing from international organizations that provide lower capital costs. Relatively new solar PV companies in Myanmar have highly educated human resources, and can thus prepare satisfactory proposals that withstand screening at the international level. The older existing mini-grids are mostly household industries, and often, the operators are unfamiliar with information technology tools, such as Microsoft Excel, that are used to prepare proposals.

- Community acceptance $[37,39,42]$

Unlike personal use equipment, such as SHSs, a mini-grid project requires a certain proportion of community acceptance for implementation.

- Ethnic/language difference.

Myanmar has 135 ethnic groups [81] and some of them do not speak the official language, Burmese. The residential areas of minor ethnic groups overlap with the off-grid areas. Language, cultural differences, and the reliability of the national government contribute to the difficulty of the projects.

\section{- $\quad$ Perception of inferior quality $[39,43,79]$}

Despite a careful feasibility study, it is difficult to seamlessly supply electricity for $24 \mathrm{~h}$ a day, 7 days a week from the early stages. The national grid also cannot offer this.

\subsubsection{Financial Barriers}

- Access to financing/high capital cost $[29,37,42,63,65,66,68,71,75]$

In addition to the energy sector, the financial sectors in Myanmar require further development. Financial institutions do not have much experience in financing, and loan financing is limited. They are therefore less experienced with financing projects and lack the knowledge for project evaluation. This makes it difficult for developers to access financing. Even if they can arrange loans, the terms are unattractive with short periods, such as one year, and a high interest rate. The legal ceiling on bank loan rates is $13 \%$ per year [82]. Mini-grid projects are relatively small, and hence, the funding cost increases.

\section{- Customers' insufficient capital [37,39,63]}

Customers also face financial difficulties. Microfinance is one of the funding options. In Myanmar, loan amounts through microfinance are increasing and accounted for $3 \%$ of the total loans in the country in 2016 [83]. The legal ceiling for microfinance interest rates is 3.5\% per month, the average interest rate is $2.5 \%$ per month, and the maximum loan amount is USD 4000 [84]. Microfinance is intended for small businesses and is unsuitable at the scale of mini-grid businesses. It is primarily designed for the customers of mini-grids rather than the developers/operators. It should be noted that the microfinance interest rate is significantly below the $10 \%$ per month interest rate of informal money-lenders. In Myanmar, interest is generally calculated on a simple interest basis [85]. 


\section{- Currency risk $[63,86]$}

If financing is not based on the local currency, companies are exposed to an exchange rate risk because their revenues and expenses are in different currencies. Between 27 April 2013 and 26 April 2018, the record low was 885 MMK/USD on 27 April 2013 and the record high was 1381 MMK/USD on 22 December 2016 [87]. Foreign financial institution contracts are normally based on the US dollar, which leaves the currency risk on the Myanmar side of the transaction.

\section{Results}

Figure 1 shows the hierarchized barriers. Respondents were asked to compare the barrier factors under the same categories. Among the barrier categories, economic, technical, and regulatory categories showed relatively high consensuses, whereas the social/cultural and financial barriers showed poor consensuses; hence, their results were clustered for further analysis.

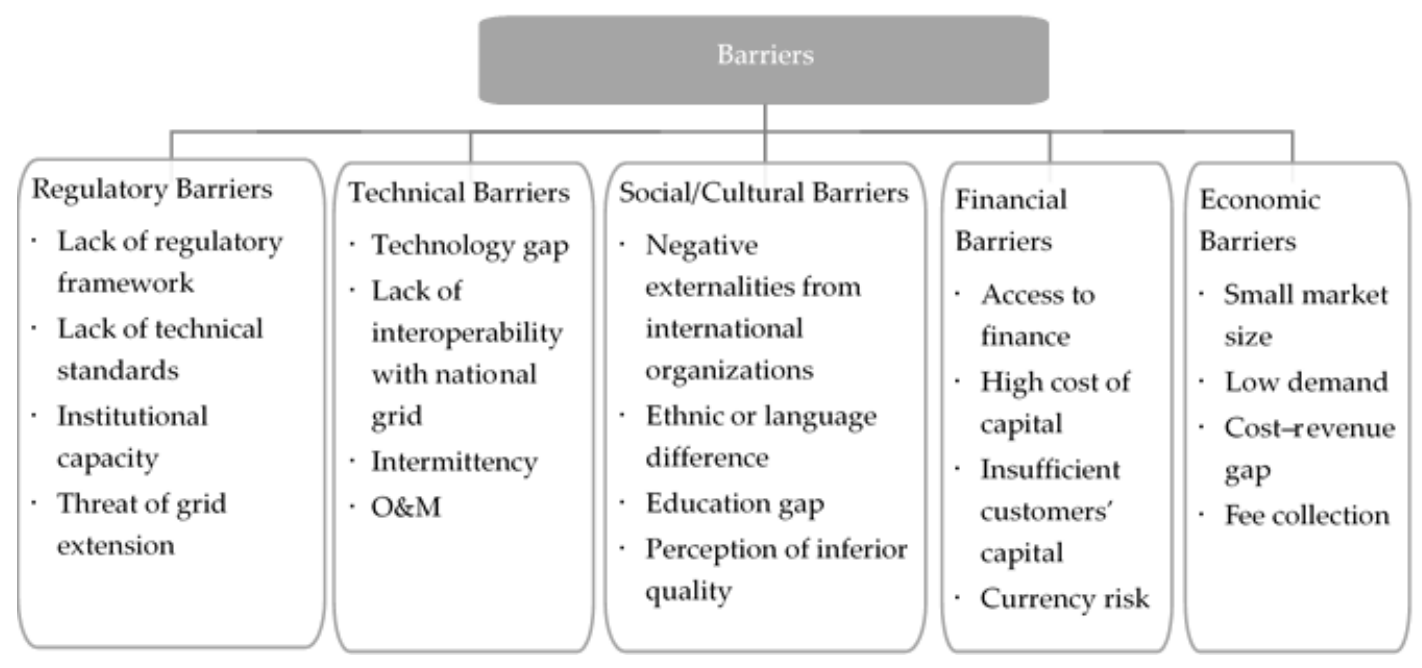

Figure 1. Hierarchized barriers. O\&M: Operation and maintenance.

\subsection{Barriers with Relatively High Consensuses}

Figure 2 shows the results of the prioritization of the economic, technical, and regulatory categories, which showed relatively high consensuses.

For economic barriers, the consensus indicator was calculated to be $61 \%$. The "cost-revenue gap" with a weight of 0.37 and "fee collection" with a weight of 0.29 scored higher than "low demand" with a weight of 0.19 and "small market size" with a weight of 0.14 .

For technical barriers, the consensus indicator was $60 \%$. "O\&M" was considered the most important with a weight of 0.36 . The score was higher than that of the other factors, such as "lack of interoperability with the main grid" with a weight of 0.26 , "intermittency" with a weight of 0.20 , and "technology gap" with a weight of 0.19 .

For regulatory barriers, the consensus indicator was 57\%, with "lack of regulatory framework" being the most prioritized with a weight of 0.31 , followed by "threat of grid extension" with a weight of 0.26 , "institutional capacity" with a weight of 0.24 , and "lack of technical standards" with a weight of 0.20 . The stakeholders judged the importance of these barrier factors to be relatively even. 


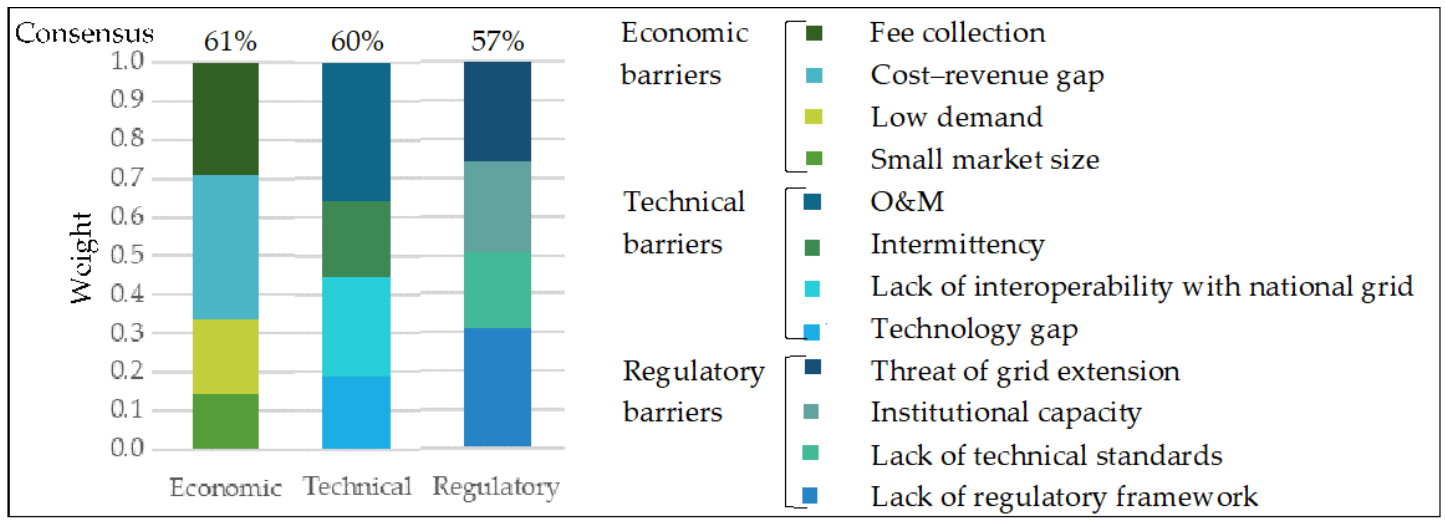

Figure 2. Weights of factors of economic, technical and regulatory barriers.

\subsection{Barriers with Low Consensuses}

The social/cultural and financial barriers showed poor consensuses of $46 \%$ and $44 \%$ in each category, respectively. Therefore, we clustered the results using the K-means method as shown in Figure 3. We decided on the number of clusters being three because the number of valid answers was limited and a small number in one cluster was difficult to analyze. After clustering, the consensus indicators increased significantly, and averaging the results in each cluster was considered reasonable. For the social/cultural barriers, cluster 1, which included eleven valid responses with a consensus indicator of $86 \%$, prioritized "perception of inferior quality." In contrast, cluster 2, which included eight responses with a consensus of $91 \%$, prioritized "education gap." Cluster 3, which included six responses, prioritized "ethnic or language difference"; however, its weight was lower than that of the most highly ranked barrier factors in the other clusters. The opinions were divided into each cluster.

For the financial barriers, the number of valid answers in each cluster was split into three clusters of 7, 6, and 6 barriers each. Cluster 1 with a $75 \%$ consensus prioritized "currency risk," cluster 2 with $83 \%$ consensus prioritized "access to finance," and cluster 3 with $70 \%$ consensus prioritized "insufficient customers' capital." The prioritizations differed between clusters. The trends of the clusters differed not only for prioritization, but also for subordination. Because the number of valid responses and the level of consensus of each cluster were similar, deciding on only one main barrier factor in the financial category was considered inappropriate.

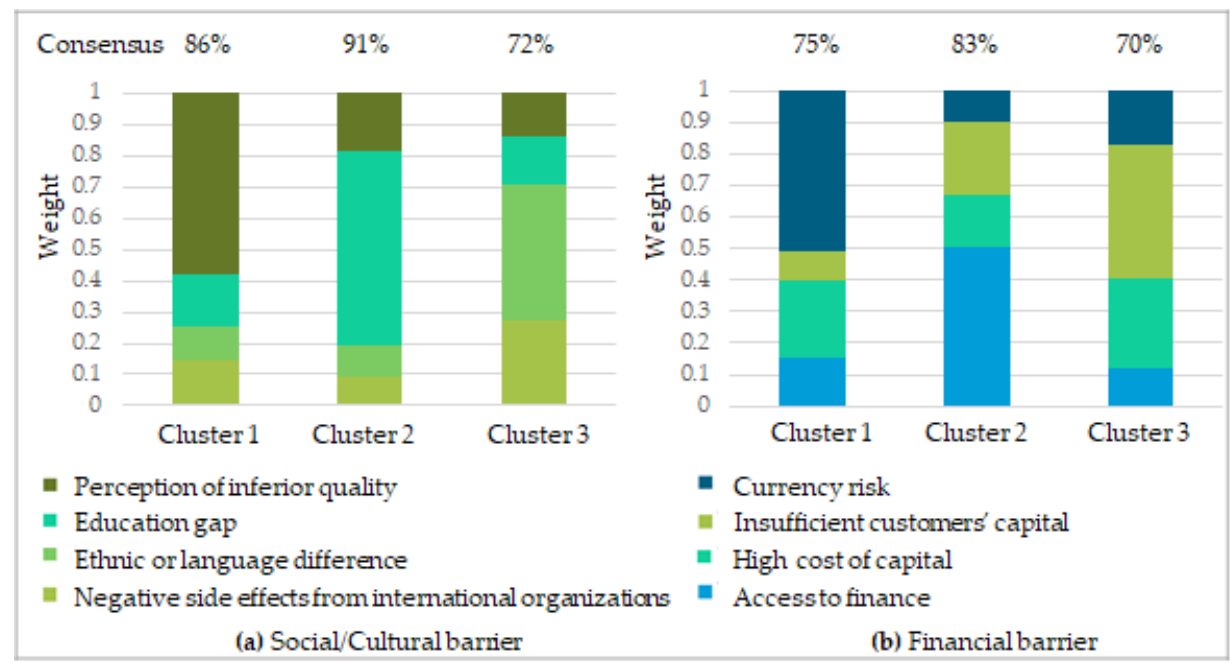

Figure 3. Averaged weights of clustered results. 


\section{Discussion and Conclusions}

In some categories, relatively higher consensuses were observed between the respondents, while in other categories, opinions were divided. Definite findings were not obtained, such as the greatest barrier to mini-grid development being the threat of national grid extension in India [39], or more broadly, such as the most important barrier to adoption of renewables being the lack of political commitment in India [29] or political instability in Nepal [30]. Furthermore, we investigated whether the occupations of the respondents tended to affect their responses; however, we observed no particular tendency related to occupation for any of the categories. The results indicate that there are various barriers to the dissemination of mini-grids based on renewable energy in Myanmar, and a consensus has yet to be reached on the greatest barrier. Nevertheless, the barriers in each category that were prioritized provide some indication of the barriers that need to be overcome.

The stakeholders of mini-grids in Myanmar accorded lower scores to "low demand" and "small market size" than to "cost-revenue gap" and "fee collection" among the economic barrier factors, which suggest that they are optimistic about the growth of the renewable energy market and increase in demand in Myanmar. The "cost-revenue gap" was prioritized, and this issue could be considered as a problem of tariff-setting. Solar power generation is particularly capital-intensive, and it is a business model that recovers the initial costs from electricity charges. The consumers' ability to pay is limited, and a high tariff to recover costs will lead to the consumers refraining from using electricity. Balancing the consumers' ability to pay and cost recovery is therefore necessary. The acceptance of the tariff by the residents depends largely on the reference price. Myanmar has subsidized the residential prices for national grid electricity, and although the government increased the tariff in 2019, for residential customers, it remains low, from 35-50 MMK/kWh (2.4-3.4 US cents $/ \mathrm{kWh})$ to 35-125 MMK/kWh (2.4-8.6 US cents/kWh) [88]. This may hamper mini-grid businesses [38]. According to our interviews, the tariff of mini-grids is 350-500 MMK/kWh (24-34 US cents/kWh), even for the mini-grids subsidized to $60 \%$ of capital expenditure. The price of mini-grids will seem high if residents consider the price of the national grid; therefore, the implementation of mini-grids depends on the balance between price and the convenience of electricity. Nevertheless, in the villages that originally relied on diesel power, the electricity generated by mini-grids based on solar power is cheaper than diesel, which is more expensive in rural areas than in urban areas. Villagers in those areas are willing to pay the tariff for mini-grids. This indicates that the reference price is important and deeply affects the behavior of the customers.

For technical barriers, "O\&M" was prioritized. Mini-grids in Myanmar are mostly located in rural areas where the national grid has not yet reached, and there are fewer electrical engineers in such areas. It is assumed that this prioritization is because mini-grid developers/operators face O\&M issues in the early stages of their businesses. To solve this issue, many villagers are trained in mini-grid operation and maintenance, and are hired for daily operations. This leads to job creation in the villages in an area that is not agriculture, which is the main industry in most rural villages of Myanmar. During our interview, it was pointed out that most people who are in their most productive years leave the villages to work in cities due to the lack of job opportunities in villages. Therefore, job creation is important for the development of villages.

"Lack of regulatory framework" was prioritized among the regulatory barriers, and was acknowledged as an issue that needs to be resolved. In this regard, Deutsche Gesellschaft für Internationale Zusammenarbeit and other international organizations have been assisting DRD in drafting regulations for mini-grids [67]; however, these regulations have not yet been published. It is assumed that the regulations will include the treatment of mini-grids when the national grid arrives and will reduce the threat of national grid extension that is ranked second in the prioritization.

Although the responders' opinions were divided regarding the social/cultural category, measures to overcome the high-ranked barrier factors can be considered. For "perception of inferior quality," it will be important to explain to the residents the characteristics of renewable energy. The output of mini-grids that use solar power, hydropower, and other renewable energies could be affected by 
weather conditions, which may hinder the potential to secure quality. Sufficient power generation and transmission would require enhancements in installation capacity and backup power-supply capacity. However, the additional facilities would increase the costs. To avoid excess capacity and ensure smooth operation, public relations should be accorded high importance.

Further, the education gap can be overcome. It was pointed out that local mini-grid operators face greater difficulty in accessing soft loans or subsidized programs than the international players who can speak English and use tools such as computers and Microsoft Office. In contrast, existing local operators are often based in rural areas, where the net high school enrollment was 39\% in 2017 [89]. It is, therefore, challenging for them to prepare the required documents for low-interest financing from international donor organizations, such as the Excel-based finance model required for 60/20/20 under the National Electrification Project. This limits their access to favorable finances.

The financial barrier category is a divisive subject. One reason for this is probably the immaturity of the Myanmar financial sector. For example, commercial banks are unfamiliar with financing projects, and mini-grid developers need sufficient equity capital. This makes it difficult to enter the capital-intensive renewable-energy-based mini-grid businesses. Several programs have been introduced to the banking sector for capacity building [90], and the success of these programs is highly desirable.

The present research has some limitations. For the AHP, prioritization is first performed between the factors that were lowest in the hierarchy and then performed one level higher. We could not conduct online surveys, and thus, it was impossible to immediately calculate the prioritization of sub-categories, ask respondents to compare the highest-ranked factors across the categories, and then determine the absolute weights of all the barrier factors. To extend our study, it is desirable to conduct a tiered survey using information technology tools with larger samples. In addition, there are known limitations to the AHP. It is practically difficult to ask respondents to repeat evaluations as even their judgment is inconsistent [36]. Moreover, the averaging of results leads to an insufficient reflection of the opinions of minorities. To avoid this, a consensus indicator is useful at allowing for clustering results to take up these opinions. Although several large barriers hinder the deployment of renewable-energy-based mini-grids in Myanmar, evaluating the weights of barrier factors and considering measures will help in overcoming the barriers.

Though we focused on the barriers in Myanmar, some of them are common with those in other countries. Thus, the efforts made in other countries can be implemented in Myanmar and vice versa. A comparative study of the barriers among countries can be carried out for further study. Moreover, Myanmar is one of the rare countries where local mini-grids have developed in a self-sustaining way during the period of national isolation under the military regime. After the subsidization period for diffuse renewable energy sources, recommendations can be derived from social-welfare mini-grid operations to make mini-grid businesses sustainable.

Author Contributions: Conceptualization, M.S. and M.N.; methodology, M.S., G.M., and M.N.; validation, M.S.; formal analysis, M.N.; investigation, M.N.; data curation, M.N.; writing-original draft preparation, M.N.; writing—review and editing, M.S. and G.M.; visualization, M.N.; supervision, M.S. and G.M.; project administration, M.S. All authors have read and agree to the published version of the manuscript.

Funding: This research was funded by the Economic Research Institute for ASEAN and East Asia (ERIA).

Acknowledgments: This work is the culmination of the research project partially reported in Chapter 4 of Yoshikawa, H., \& Anbumozhi, V. (Eds.) (2019) Shaping Energy Policies to Achieve the Sustainable Development Goals in Myanmar and the Greater Mekong Subregion. ERIA, and Chapter 5 of Yoshikawa, H., \& Anbumozhi, V. (Eds.) (2018) Electricity Futures in the Greater Mekong Subregion: Towards Sustainability, Inclusive Development, and Conflict Resolution. ERIA.

Conflicts of Interest: The authors declare no conflict of interest. 


\section{References}

1. IEA; IRENA; UNSD; WB; WHO. Tracking SDG 7: The Energy Progress Report 2019 Executive Summary; WHO: Washington, DC, USA, 2019.

2. Climatescope 1Q 2019 Off-Grid and Mini-Grid Market Outlook. Available online: https://medium.com/ climatescope/1q-2019-off-grid-and-mini-grid-market-outlook-ec4a400ced93 (accessed on 17 April 2019).

3. Ministry of Electricity and Energy Myanmar NEP Plan. Available online: http://www.moee.gov.mm/en/ ignite/page/80 (accessed on 20 April 2018).

4. Myanmar Energy Monitor; Frontier Myanmar Research Ltd.: Yangon, Myanmar, 2019.

5. Billen, D.; Bianchi, G. Decentralised Energy Market Assessment in Myanmar; Smartpower: Yangon, Myanmar, 2019.

6. Department of Population Ministry of Immigration and Population. The 2014 Myanmar Population and Housing Census The Union Report: Occupation and Industry Census Report; Department of Population Ministry of Immigration and Population: Nay Pyi Taw, Myanmar, 2015; Volume 2-B.

7. Ministry of Planning and Finance Myanmar; World Bank. An Analysis of Poverty in Myanmar: Part 02 Poverty Profile; Ministry of Planning and Finance Myanmar: Nay Pyi Taw, Myanmar; World Bank: Washington, DC, USA, 2017.

8. IRENA. REthinking Energy 2017: Accelerating the Global Energy Transformation; IRENA: Abu Dhabi, UAE, 2017; Volume 55.

9. Schnitzer, D.; Lounsbury, D.S.; Carvallo, J.P.; Deshmukh, R.; Apt, J.; Kammen, D.M. Microgrids for Rural Electrification; United Nations Foundation: New York, NY, USA, 2014.

10. BNEF. 2Q 2017 Frontier Power Market Outlook Micro-Grids on the Horizon; Bloomberg New Energy Finance: New York, NY, USA, 2017.

11. ADB. Myanmar: Energy Sector Assessment, Strategy, and Road Map; Asian Development Bank: Manila, Philippines, 2016.

12. ADB. Renewable Energy Developments and Potential in the Greater Mekong Subregion; Asian Development Bank: Manila, Philippines, 2015.

13. Yoshikawa, H.; Anbumozhi, V. Electricity Futures in the Greater Mekong Subregion: Towards Sustainability, Inclusive Development, and Conflict Resolution; Yoshikawa, H., Anbumozhi, V., Eds.; Economic Research Institute for ASEAN and East Asia: Jakarta, Indonesia, 2018; Volume 8.

14. Pyithu Hluttaw. The 12th Regular Session of the 2nd Pyithu Hluttaw (27.5.2019). Available online: https: //www.youtube.com/watch?v=WQ0K10G_Tas\&feature=youtu.be (accessed on 24 January 2020). (In Burmese)

15. JICA; NEWJEC Inc. The Kansai Electric Power Data Collection Survey on Capacity Development of Power Sector Development Planning in the Republic of the Union of Myanmar; JICA: Tokyo, Japan, 2015.

16. The Republic of the Union of Myanmar. Myanmar's Intended Nationally Determined Contribution-INDC; The Government of the Republic of the Union of Myanmar: Naypyidaw, Myanmar, 2015.

17. Del Barrio-Alvarez, D.; Sugiyama, M. Toward a Sustainable Electricity Policy in Myanmar: Recommendations for Policy Makers and Development Partners; PARI: Tokyo, Japan, 2018.

18. Greacen, C. Myanmar Mini-Grid Overview. Available online: https://www.esmap.org/sites/default/files/ GreacenESMAPMyanmarminigridsituation_Optimized.pdf (accessed on 1 July 2017).

19. ADB. Developing Renewable Energy Mini-Grids in Myanmar; ADB: Manila, Philippines, 2018.

20. World Bank. Myanmar-National Electrification Project: Environmental Assessment: Environmental and Social Management Framework; World Bank: Washington, DC, USA, 2018; Volume 1.

21. JICS. Nenpo 2016; JICS: Tokyo, Japan, 2016. (In Japanese)

22. Numata, M.; Sugiyama, M.; Mogi, G.; Swe, W.; Anbumozhi, V. Technoeconomic Assessment of Microgrids in Myanmar; ERIA: Jakarta, Indonesia, 2018.

23. Zangeneh, A.; Jadid, S.; Rahimi-Kian, A. A hierarchical decision making model for the prioritization of distributed generation technologies: A case study for Iran. Energy Policy 2009, 37, 5752-5763. [CrossRef]

24. Kablan, M. Prioritization of decentralized electricity options available for rural areas in Jordan. Energy Convers. Manag. 1997, 38, 1515-1521. [CrossRef]

25. Wang, X.; Feng, Z. Sustainable development of rural energy and its appraising system in China. Renew. Sustain. Energy Rev. 2002, 6, 395-404. [CrossRef] 
26. Aras, H.; Erdoğmuş, Ş.; Koç, E. Multi-criteria selection for a wind observation station location using analytic hierarchy process. Renew. Energy 2004, 29, 1383-1392. [CrossRef]

27. Lee, S.K.; Yoon, Y.J.; Kim, J.W. A study on making a long-term improvement in the national energy efficiency and GHG control plans by the AHP approach. Energy Policy 2007, 35, 2862-2868. [CrossRef]

28. Wijayatunga, P.D.C.; Siriwardena, K.; Fernando, W.J.L.S.; Shrestha, R.M.; Attalage, R.A. Strategies to overcome barriers for cleaner generation technologies in small developing power systems: Sri Lanka case study. Energy Convers. Manag. 2006, 47, 1179-1191. [CrossRef]

29. Luthra, S.; Kumar, S.; Garg, D.; Haleem, A. Barriers to renewable/sustainable energy technologies adoption: Indian perspective. Renew. Sustain. Energy Rev. 2015, 41, 762-776. [CrossRef]

30. Ghimire, L.P.; Kim, Y. An analysis on barriers to renewable energy development in the context of Nepal using AHP. Renew. Energy 2018, 129, 446-456. [CrossRef]

31. Limmeechokchai, B.; Chawana, S. Sustainable energy development strategies in the rural Thailand: The case of the improved cooking stove and the small biogas digester. Renew. Sustain. Energy Rev. 2007, 11, 818-837. [CrossRef]

32. Nagesha, N.; Balachandra, P. Barriers to energy efficiency in small industry clusters: Multi-criteria-based prioritization using the analytic hierarchy process. Energy 2006, 31, 1633-1647. [CrossRef]

33. Shi, H.; Peng, S.Z.; Liu, Y.; Zhong, P. Barriers to the implementation of cleaner production in Chinese SMEs: Government, industry and expert stakeholders' perspectives. J. Clean. Prod. 2008, 16, 842-852. [CrossRef]

34. Goepel, K.D. Implementing the Analytic Hierarchy Process as a Standard Method for Multi-Criteria Decision Making in Corporate Enterprises-A New AHP Excel Template with Multiple Inputs. In Proceedings of the International Symposium on the Analytic Hierarchy Process 2013, Kuala Lumpur, Malaysia, 23-26 June 2013; pp. 1-10.

35. Business Performance Management Singapore (BPMSG) AHP Consensus Indicator. Available online: https://bpmsg.com/ahp-consensus-indicator/ (accessed on 25 January 2020).

36. Keeley, A.R.; Matsumoto, K. Relative significance of determinants of foreign direct investment in wind and solar energy in developing countries-AHP analysis. Energy Policy 2018, 123, 337-348. [CrossRef]

37. Painuly, J.P. Barriers to renewable energy penetration: A framework for analysis. Renew. Energy 2001, 24, 73-89. [CrossRef]

38. Karatayev, M.; Hall, S.; Kalyuzhnova, Y.; Clarke, M.L. Renewable energy technology uptake in Kazakhstan: Policy drivers and barriers in a transitional economy. Renew. Sustain. Energy Rev. 2016, 66, 120-136. [CrossRef]

39. Comello, S.D.; Reichelstein, S.J.; Sahoo, A.; Schmidt, T.S. Enabling Mini-Grid Development in Rural India. World Dev. 2017, 93, 94-107. [CrossRef]

40. Sen, S.; Ganguly, S. Opportunities, barriers and issues with renewable energy development-A discussion. Renew. Sustain. Energy Rev. 2017, 69, 1170-1181. [CrossRef]

41. Gabriel, C.A. What is challenging renewable energy entrepreneurs in developing countries? Renew. Sustain. Energy Rev. 2016, 64, 362-371. [CrossRef]

42. Nasirov, S.; Silva, C.; Agostini, C.A. Investors' Perspectives on Barriers to the Deployment of Renewable Energy Sources in Chile. Energies 2015, 8, 3794-3814. [CrossRef]

43. Bhattacharyya, S.C.; Palit, D. Mini-Grids for Rural Electrification of Developing Countries: Technical Aspects of Mini-Grids for Rural Electrification; Bhattacharyya, S.C., Palit, D., Eds.; Springer: Berlin, Germany, 2014; ISBN 978-3-319-04815-4.

44. Saaty, R.W. The analytic hierarchy process-What it is and how it is used. Math. Model. 1987, 9, 161-176. [CrossRef]

45. Saaty, T.L. An Exposition of the AHP in Reply to the Paper "Remarks on the Analytic Hierarchy Process". Manage. Sci. 1990, 36, 259-268. [CrossRef]

46. Saaty, T.L. Decision making with the AHP: Why is the principal eigenvector necessary. Eur. J. Oper. Res. 2003, 145, 85-91. [CrossRef]

47. Saaty, T.L. How to make a decision: The analytic hierarchy process. Eur. J. Oper. Res. 1994, 74, $426-447$. [CrossRef]

48. Saaty, T.L. The Analytic Network Process. In Decision Making with the Analytic Network Process International Series in Operations Research \& Management Science; Springer: Boston, MA, USA, 2013; pp. 1-26, ISBN 9781461472780. 
49. Saaty, T.L.; Kearns, K.P. Analytical Planning: The Organization of System; Pergamon Press: New York, NY, USA, 1985; ISBN 0080325998.

50. Soma, K. How to involve stakeholders in fisheries management-A country case study in Trinidad and Tobago. Mar. Policy 2003, 27, 47-58. [CrossRef]

51. Cox, A.M.; Alwang, J.; Johnson, T.G. Local preferences for economic development outcomes: Analytical hierarchy procedure. Growth Change 2000, 31, 341-366. [CrossRef]

52. Thao, P.T.M.; Kurisu, K.H.; Hanaki, K. Evaluation of Rice Husk Use Scenarios Incorporating Stakeholders' Preferences Revealed through the Analytic Hierarchy Process in An Giang Province, Vietnam. Low Carbon Econ. 2014, 5, 95-104. [CrossRef]

53. Madan, B.R.; Hanaoka, S. Application of Analytic Hierarchy Process for Location Analysis of Logistics Centers in Laos. In Proceedings of the 91th Annual Transportation Research Board Meeting, Washington, DC, USA, 22-26 January 2012.

54. Shannon, C.E. A mathematical theory of communication. Bell Syst. Tech. Journalystem Tech. J. 1948, 27, 379-423. [CrossRef]

55. Jost, L. Partitioning diversity into independent alpha and beta components. Ecology 2007, 88, 2427-2439. [CrossRef]

56. Qureshi, M.; Harrison, S. Application of the analytic hierarchy process to riparian revegetation policy options. Small Scale For. Econ. Manag. Policy 2003, 2, 441-458. [CrossRef]

57. Singh, R.P.; Nachtnebel, H.P. Analytical hierarchy process (AHP) application for reinforcement of hydropower strategy in Nepal. Renew. Sustain. Energy Rev. 2016, 55, 43-58. [CrossRef]

58. Melillo, P.; Pecchia, L. What Is the Appropriate Sample Size To Run Analytic Hierarchy Process in a Survey-Based Research? In Proceedings of the International Symposium of the Analytic Hierarchy Process, London, UK, 4-7 August 2016.

59. Vander Plas, J. Machine Learning: In Depth: K-Means Clustering. In Python Data Science Handbook: Essential Tools for Working with Data; O'Reilly Media: Sebastopol, CA, USA, 2016; ISBN 9781491912126.

60. Raschka, S. Python Machine Learning-Code Examples, Chapter 11-Working with Unlabeled Data-Clustering Analysis. Available online: https://github.com/rasbt/python-machine-learning-book/blob/ master/code/ch11/ch11.ipynb (accessed on 7 May 2019).

61. Scikit-Learn Selecting the Number of Clusters with Silhouette Analysis on KMeans Clustering. Available online: https://scikit-learn.org/stable/auto_examples/cluster/plot_kmeans_silhouette_analysis.html (accessed on 3 December 2019).

62. Vaghela, D. Myanmar's Renewable Energy Mini-Grids:Technology Differentiation. In Proceedings of the ADB Myanmar Off-Grid Investment Forum, Nay Pyi Taw, Myanmar, 9 May 2017; p. 11.

63. Gershenson, D.; Tilleard, M.; Cusack, J.; Cooper, D.; Monk, A.; Kammen, D. Increasing Private Capital Investment into Energy Access: The Case for Mini-Grid Pooling Facilities; UNEP: Nairobi, Kenya, 2015.

64. Alstone, P.; Gershenson, D.; Kammen, D.M. Decentralized energy systems for clean electricity access. Nat. Clim. Chang. 2015, 5, 305-314. [CrossRef]

65. Schmidt, T.S.; Blum, N.U.; Wakeling, R.S. Attracting private investments into rural electrification-A case study on renewable energy based village grids in Indonesia. Energy Sustain. Dev. 2013, 17, 581-595. [CrossRef]

66. Greacen, C. Role of Mini-Grids for Electrification in Myanmar-SWOT Analysis and Roadmap for Scale Up; World Bank: Washington, DC, USA, 2017.

67. Du Pont, P. Decentralizing Power:The Role of State and Region Governments in Myanmar's Energy Sector; Tha Asia Foundation: Yangon, Myanmar, 2019.

68. Ahlborg, H.; Hammar, L. Drivers and barriers to rural electrification in Tanzania and Mozambique-Grid-extension, off-grid, and renewable energy technologies. Renew. Energy 2014, 61, 117-124. [CrossRef]

69. Bhattacharyya, S.C. To regulate or not to regulate off-grid electricity access in developing countries. Energy Policy 2013, 63, 494-503. [CrossRef]

70. Kyaw, M.M. Power Development Opportunities in Myanmar. In Proceedings of the Myanmar Investment Forum, Nay Pyi Taw, Myanmar, 6-7 June 2017.

71. UNCDF/UNDP. CleanStart-Microfinance Opportunities for a Clean Energy Future; UNCDF: New York, NY, USA, 2012. 
72. Kobayakawa, T.; Kandpal, T.C. Photovoltaic micro-grid in a remote village in India: Survey based identification of socio-economic and other characteristics affecting connectivity with micro-grid. Energy Sustain. Dev. 2014, 18, 28-35. [CrossRef]

73. Hasan, F. ARE Newsletter April 2018: Off-Grid Investments: Financing \& Funding in Focus. Available online: https://www.ruralelec.org/newsletter/are-newsletter-april-2018-grid-investmentsfinancing-funding\#guest-editorial-1638 (accessed on 26 April 2018).

74. Tenenbaum, B.; Greacen, C.; Vaghel, D. Mini-Grids and Arrival of the Main Grid: Lessons from Cambodia, Sri Lanka, and Indonesia; ESMAP: Washington, DC, USA, 2017.

75. Palit, D.; Chaurey, A. Off-Grid Rural Electrification Experiences from South Asia. Green Energy Technol. 2011, 15, 266-276.

76. Takahashi, A. Sosei No Myanmar; Akashi Shoten: Tokyo, Japan, 2018; ISBN 9784750346489. (In Japanese)

77. Swe, M.A. Burma-Union of Grain and Feed Annual 2018 Annual Report; USDA: Washington, DC, USA, 2018.

78. Tenenbaum, B.; Greacen, C.; Siyambalapitiya, T.; Knuckles, J. From the Bottom Up; World Bank: Washungton, DC, USA, 2014; ISBN 9781464800931.

79. Franz, M.; Peterschmidt, N.; Rohrer, M.; Kondev, B. Mini-Grid Policy Toolkit; EUEI: Eschborn, Germany, 2014.

80. Blum, N.U.; Sryantoro Wakeling, R.; Schmidt, T.S. Rural electrification through village grids-Assessing the cost competitiveness of isolated renewable energy technologies in Indonesia. Renew. Sustain. Energy Rev. 2013, 22, 482-496. [CrossRef]

81. Central Intelligence Agency. The World Fact Book: East Asia/Southeast Asia: Burma. Available online: https://www.cia.gov/library/publications/the-world-factbook/geos/bm.html (accessed on 22 April 2019).

82. Gilmore, S.; Robinson, G. Myanmar moves to stave off credit crunch. Nikkei Asian Review, 22 September 2017.

83. Ono, Y. How microfinance can help Myanmar meet its major funding needs. Nikkei Asian Review, 27 April 2017.

84. Dave Grace and Associates Myanmar Microfinance Regulatory Benchmarking Survey. Available online: http://mekongbiz.org/wp-content/uploads/2017/02/ADB-MBI-MF-Benchmarking-Survey-10-Oct16final-proof-DG-AB.pdf (accessed on 15 April 2018).

85. Takahashi, A. Gendai Myanmar No Noson-Keizai: Iko-Keizai-ka No Nomin to Hi-Nomin [Myanmar's Village Economy in Transition: Peasants' Lives under the Market.-Oriented Economy]; University of Tokyo Press: Tokyo, Japan, 2000; ISBN 978-4-13-046066-8. (In Japanese)

86. Bloomberg NEF. Emerging Markets Outlook 2018: Energy Transition in the World's Fastest Growing Economies; Bloomberg NEF: London, UK, 2018.

87. XE.com XE Currency Charts: USD to MMK. Available online: https://xe.com/currencycharts/?from=USD\& to $=$ MMK\&view=5Y (accessed on 26 April 2018).

88. XE.com XE Currency Converter-Live Rates: 1 US Dolloar to Burmese Kyat. Available online: https://www. xe.com/currencyconverter/convert/?Amount=1\&From=USD\&To=MMK (accessed on 28 January 2020).

89. Central Statistical Organization; UNDP; World Bank. Myanmar Living Conditions Survey 2017: Key Indicators Report; World Bank: Washington, DC, USA, 2018.

90. Hofmann, A. Banking and Financial Sector Development (BFSD) in Myanmar. Available online: https: //www.giz.de/en/downloads/giz2017-en-financial-sector-myanmar.pdf (accessed on 29 January 2020).

(C) 2020 by the authors. Licensee MDPI, Basel, Switzerland. This article is an open access article distributed under the terms and conditions of the Creative Commons Attribution (CC BY) license (http://creativecommons.org/licenses/by/4.0/). 